\section{Sodium Bisulfite Analysis of the Methylation Status of DNA from Small Portions of Paraffin Slides}

BioTechniques 31:1004-1008 (November 2001)

DNA methylation at $\mathrm{CpG}$ dinucleotides has been intensely studied to elucidate its roles in normal and aberrant cellular processes, including genomic imprinting, modulation of transcription, $\mathrm{X}$-inactivation, gene silencing, and carcinogenesis. A number of techniques for the detection of methylated cytosines within a DNA sequence have been developed, and these have been refined and improved over time. DNA methylation analysis involving the conversion of genomic DNA by the sodium bisulfite technique, coupled with cloning and sequencing, is a powerful method for ascertaining the methylation status of individual cytosine residues within a continuous stretch of DNA (2-4). In this method, unmethylated cytosines are converted to uracil residues via a series of chemical treatments, including incubation with sodium bisulfite (8-10), while methylated cytosines remain unmodified. A segment of treated DNA can then be amplified by PCR, resulting in the representation of unmethylated cytosines by thymine residues, and the PCR product can be cloned and sequenced. By comparing the original and bisulfite-converted sequences, unmethylated cytosines can be identified by their position in the thymine lane, in contrast with methylated cytosines, which maintain their normal positions as cytosines. Aside from the ability to determine the methylation status of every cytosine residue within the PCR product, the sodium bisulfite method has the further advantage of requiring smaller quantities of starting DNA than many other methods. More recent modifications of the protocol have further reduced the amount of starting material needed by embedding DNA or cells in agarose to retain the genetic material through a series of washes and to keep DNA in a denatured state. This allows for full reactivity of sodium bisulfite (7).

For many applications, particularly those investigating the connection between aberrant DNA methylation and cancer, archival, formalin-fixed, paraffin-embedded specimens would be a desirable starting material. However, the heterogeneity and close proximity of normal tissue inherent in many tumors on a microscopic scale, coupled with the difficulties associated with extracting sufficient quantities of DNA from small volumes of paraffin to perform methylation analysis, have rendered these archival specimens of limited use. Here, we present a simple protocol for performing sodium bisulfite sequencing on pieces of paraffinembedded tissue sections with areas as small as $1 \mathrm{~mm}^{2}$.

Intact glass microscope slides containing $10-\mu \mathrm{m}$ sections of formalinfixed, paraffin embedded human liver, a $10-\mu \mathrm{m}$ section of normal human breast tissue, or a $5-\mu \mathrm{m}$ section of breast tumor tissue were deparaffinized through $3 \times$ 5 -min washes in xylene, followed by rehydration in descending alcohols: $100 \%, 2 \times 2 \mathrm{~min} ; 95 \%, 2 \times 2 \mathrm{~min} ; 70 \%$, 30 s. Slides were then soaked in PBS. The desired portions of each slide as described in Table 1 were then carefully scraped away with razor blades and sterile pipet tips and put into $600-\mu \mathrm{L}$ tubes.

Small quantities of lysis buffer $\left(20-50 \mu \mathrm{L} ; 0.5 \%\right.$ Tween $^{\circledR} 20$ in TE) and proteinase $\mathrm{K}(10 \mathrm{mg} / \mathrm{mL})$ were added to tubes as shown in Table 1. Mineral oil was added to each tube; all tubes were then centrifuged briefly to ensure that tissue and proteinase $\mathrm{K}$ were contained in the aqueous phase. Tubes were incubated for three days at $65^{\circ} \mathrm{C}$, with the addition of proteinase $\mathrm{K}$ every $24 \mathrm{~h}$ as described in Table 1. Following the fourth and final addition of proteinase $\mathrm{K}$, samples were incubated for $1 \mathrm{~h}$ at $65^{\circ} \mathrm{C}$ and then heated to $95^{\circ} \mathrm{C}$ for $5 \mathrm{~min}$.

For each bead, $9 \mu \mathrm{L}$ molten $2 \%$ low-melt agarose were heated to $80^{\circ} \mathrm{C}$ and mixed with $1 \mu \mathrm{L}$ digested tissue solution. A $10-\mu \mathrm{L}$ aliquot of this mixture was then carefully dropped into $500 \mu \mathrm{L}$ ice-cold mineral oil and either stored at $4^{\circ} \mathrm{C}$ or used directly in the following steps. Sodium bisulfite conversion of agarose-embedded genomic DNA was performed as described (7), beginning with a series of washes in TE. All washes were performed in $500 \mu \mathrm{L}$ solution. To determine the efficacy of the technique in converting DNA from small amounts of paraffin embedded tissue, a 305-bp portion of the estrogen receptor- $\alpha$ gene (GenBank ${ }^{\circledR}$ accession no. X03635) CpG island was amplified by PCR with semi-nested primers; the need for nested or semi-nested primers is gene and primer-pair dependent and was determined empirically. All PCRs were hot started with $1 \mu \mathrm{L}$ of the reverse primer and carried out under the following conditions: 5 cycles at $94^{\circ} \mathrm{C}$ for $20 \mathrm{~s}, 55^{\circ} \mathrm{C}$ for $30 \mathrm{~s}, 72^{\circ} \mathrm{C}$ for $45 \mathrm{~s}$, followed by 30 cycles at $94^{\circ} \mathrm{C}$ for $25 \mathrm{~s}$, $55^{\circ} \mathrm{C}$ for $40 \mathrm{~s}, 72^{\circ} \mathrm{C}$ for $25 \mathrm{~s}$, and a final extension step at $72^{\circ} \mathrm{C}$ for $16 \mathrm{~min}$. In the first round of amplification, outside forward primer DR73 (5'-TGATTTTTTATAAAGTATTTGGGATGG-3') and reverse primer DR208 (5'-ATACAA TAACATCAACAAACTCAAAAACAC-3') were used to amplify directly from the agarose/DNA slurry in a 50-


Figure 1. PCR product $(15 \mu \mathrm{L})$ from amplification of bisulfite-treated, paraffin-embedded liver DNA samples were electrophoresed on a non-denaturing, $6 \%$ polyacrylamide gel and stained with ethidium bromide. The 305-bp PCR products are arranged in descending order relative to the total area of starting material. Lane 1,36 mm² lane 2, $25 \mathrm{~mm}^{2}$; lane 3, $16 \mathrm{~mm}^{2}$; lane 4, $9 \mathrm{~mm}$; and lane 5, $1 \mathrm{~mm}^{2}$. 
Table 1. Sizes and Volumes of Tissue Sections, Lysis Buffer, and Proteinase K in Each Reaction

\begin{tabular}{|clll|}
\hline $\begin{array}{c}\text { Section Size } \\
\left(\mathbf{m m}^{2}\right)\end{array}$ & Tissue Type & Lysis Buffer $(\mu \mathbf{L})$ & $\begin{array}{c}\text { Proteinase } \\
\text { K }(\mu \mathbf{L})\end{array}$ \\
\hline 36 & Liver & 30 & 1.00 \\
25 & Liver & 30 & 1.00 \\
16 & Liver & 25 & 0.75 \\
9 & Liver & 25 & 0.75 \\
1 & Liver & 20 & 0.50 \\
Whole & Breast & 50 & 2 \\
16 & Breast Tumor & 25 & 0.75 \\
\hline
\end{tabular}

$\mu \mathrm{L}$ reaction. An aliquot of PCR product from this reaction $(2 \mu \mathrm{L})$ was then used as template with inside forward primer DR308 (5'-GGGATGGTGTTATTG TATTAGATTTAAGGG-3') and reverse primer DR 208. PCR products were electrophoresed on a $6 \%$ polyacrylamide minigel to confirm successful amplification of a 305-bp fragment.

A PCR product from the successful conversion of paraffin-embedded human breast tissue was cloned into a Topo ${ }^{\mathrm{TM}}$ -

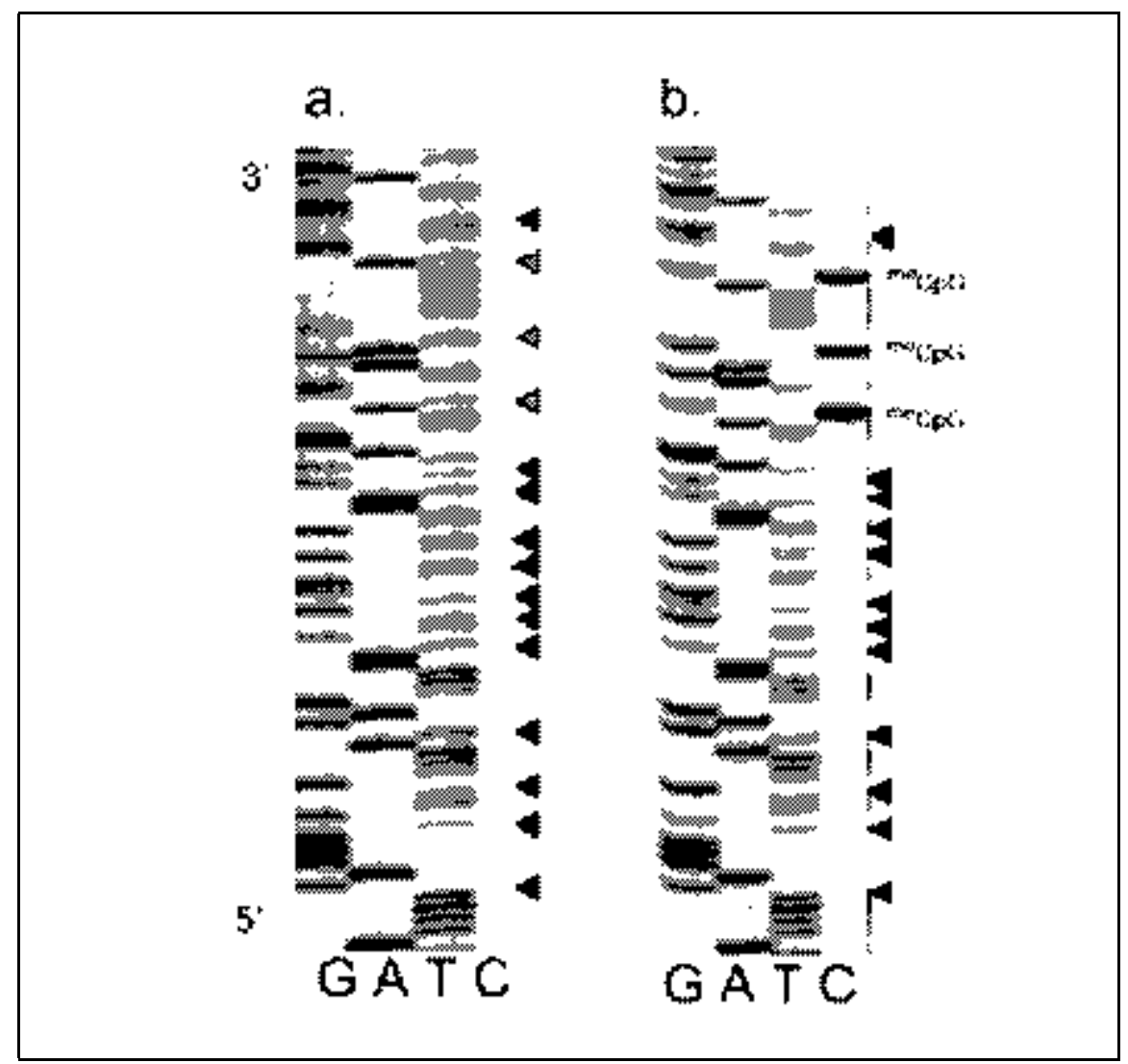

Figure 2. Representative sequences of bisulfite-treated, PCR-amplified, and cloned DNA from paraffin-embedded, normal human breast tissue or breast tumor tissue. G, A, T, and C lanes are as marked. Arrowheads denote the positions of unmethylated $\mathrm{CpG}$ dinucleotides. Methylated $\mathrm{CpG}$ dinucleotides are identified by ${ }^{\mathrm{me}} \mathrm{CpG}$. (a) Sequence from normal breast tissue. Note the complete absence of bands in the cytosine lane, which indicates that the sample contained no methylated cytosines, consistent with previous experiments on normal breast tissue using routine methods (data not shown). In this case, a false positive for complete conversion is impossible, as only complete conversion of the sample can result in a total absence of cytosine bands. (b) Sequence from breast tumor tissue. The few bands in the $\mathrm{C}$ lane identify the positions of methylated cytosines in $\mathrm{CpG}$ dinucleotides.

TA Cloning ${ }^{\circledR}$ vector (pCR ${ }^{\circledR}$ II-Topo; Invitrogen, Carlsbad, CA, USA) and manually sequenced as described previously (6). Cloning of the PCR product allows one to address allele-specific methylation and permits visualization of lowfrequency methylation at specific CpGs. Figure 1 shows a representative PCR from $5-\mu \mathrm{m}$ sections of liver that were deparaffinized and cut into squares ranging from 1 to $36 \mathrm{~mm}^{2}$. DNA from portions of sections as small as $9 \mathrm{~mm}^{2}$ could be readily amplified, and pieces of tissue as small as $1 \mathrm{~mm}^{2}$ could be amplified by PCR in some reactions. For 1and 4-mm² sections, successful amplification from converted agarose beads was dependent on the cellularity of the tissue samples used; this can likely be attributed to the dilution of a relatively small number of nuclei in a large volume of liquid. However, it is clear that sodium bisulfite conversion and amplification of a short (250-450 bp) PCR fragment from such small quantities of paraffin tissue is possible. This isolation method also allows for other types of DNA fragment analysis (i.e., SSCP), as described in other papers (1). For very small areas, efficient sodium bisulfite conversion could be accomplished by combining corresponding portions from a number of serial sections.

To test for complete conversion of template using this method and the suitability of the resulting PCR product for cloning and sequencing, an entire 10$\mu \mathrm{m}^{2}$ section of normal breast and a 16$\mathrm{m} \mathrm{m}^{2}$ portion of breast tumor tissue were deparaffinized and digested; $1 \mu \mathrm{L}$ digested tissue from each sample was used to make agarose beads, which were then converted and PCR amplified with the semi-nested estrogen receptor$\alpha$ primer pairs. The resultant PCR products were cloned and sequenced. Sequences from representative clones derived from these reactions are shown in Figure 2. For the normal breast tissue, all clones analyzed showed complete reaction with sodium bisulfite in this unmethylated sample, confirming the efficacy of our method in accessing all DNA template (Figure 2a). By comparison, the breast tumor sample was methylated at some sites (Figure 2b).

Several protocols exist for the extraction of DNA from paraffin sections, which differ in specific aspects of 
methodology (1-3,5,7). Some methods require large amounts of starting material with significant loss of total DNA $(2,3,7)$ and may be unsuitable for small or heterogeneous sections, or when the presence of contaminating tissue (such as normal cells in tumor samples) may be a problem. Our protocol differs from that in Reference 5 in that we dehydrate the tissue sections before isolating the specific regions of tissue before beginning the DNA isolation steps. This reduces the likelihood of capturing regions of contaminating tissue from the paraffin sections. As a result, our method is also directly applicable to hydrated tissue sections to be analyzed by laser capture dissection methods. Furthermore, protocols in which an entire paraffin section is scraped away and deparaffinized in solution renders dissection of a desired area impossible. Our method shows that smaller amounts of paraffin tissue can be analyzed for DNA methylation with greater sensitivity and accuracy by de- paraffinizing a single intact slide, dissecting the desired tissue sample away from the deparaffinized slide, completely digesting the tissue sample in a small volume, and embedding the digestion mixture in an agarose bead where DNA can be held in a denatured state while impurities are washed away.

With our method, we have also found that loss of DNA can be prevented by minimizing volumes of solution and avoiding unnecessary DNA purification steps (such as phenol/chloroform extraction) reported elsewhere (1). Furthermore, the methylation status of individual alleles and at individual $\mathrm{CpGs}$ can be distinguished. Also, the DNA we isolated from the microdissected tissue sections is of sufficient quality and stability that bisulfite conversion and PCR has been successful using DNA stored in the lysis buffer for 9 months after its initial isolation. The methylation status of multiple genes can also be analyzed since we have been able to use this method to analyze methylation in the BRCA1 promoter region in DNA from the same tumor samples shown in the figures (data not shown).

\section{REFERENCES}

1.Bian Y.S., P. Yan, M.C. Osterheld, C. Fontolliet, and J. Benhattar. 2001. Promoter methylation analysis on microdissected paraffin-embedded tissues using bisulfite treatment and PCR-SSCP. BioTechniques 30:66-72.

2.Clark, S.J., J. Harrison, C.L. Paul, and M. Frommer. 1994. High sensitivity mapping of methylated cytosines. Nucleic Acids Res. 22:2990-2997.

3.Feil, R., J. Charlton, A.P. Bird, J. Walter, and W. Reik. 1994. Methylation analysis on individual chromosomes: improved protocol for bisulphite genomic sequencing. Nucleic Acids Res. 22:695-696.

4.Frommer, M., L. McDonald, D.S. Millar, C.M. Collis, F. Watt, G.W. Grigg, P.L. Molloy, and C.L. Paul. 1992. A genomic sequencing protocol that yields a positive display of 5-methylcytosine residues in individual DNA strands. Proc. Natl. Acad. Sci. USA 89:1827-1831.

5.Kitazawa, S., R. Kitazawa, and S. Maeda. 2000. Identification of methylated cytosine from archival formalin-fixed paraffin-embedded specimens. Lab. Invest. 80:275-276.

6.Mancini, D.N., D.I. Rodenhiser, P.J. Ainsworth, F.P. O'Malley, S.M. Singh, W. Xing, and T.K. Archer. 1998. CpG methylation within the $5^{\prime}$ regulatory regions of the BRCA1 gene is tumor specific and includes a putative CREB binding site. Oncogene 16:1161-1169.
7.Olek, A., J. Oswald, and J. Walter. 1996. A modified and improved method for bisulphite based cytosine methylation analysis. Nucleic Acids Res. 24:5064-5066.

8.Shapiro, R., B. Braverman, J.B. Louis, and R.E. Servis. 1973. Nucleic acid reactivity and conformation. II. Reaction of cytosine and uracil with sodium bisulfite. J. Biol. Chem. 248:4060-4064.

9.Shapiro, R., V. DiFate, and M. Welcher. 1974. Deamination of cytosine derivatives by bisulfite. Mechanism of the reaction. J. Amer. Chem. Soc. 96:906-912.

10.Wang, R.Y.-H., C.W. Gehrke, and M. Ehrlich. 1980. Comparison of bisulphite modification of 5-methyldeoxycytidine and deoxycytidine residues. Nucleic Acids Res. 8:4777-4790.

A.A. is a recipient of a postgraduate scholarship from the Natural Sciences and Engineering Research Council. This research was supported in part by operating grants to D.R. from the Canadian Breast Cancer Research Initiative and the Breast Cancer Society of Canada. Address correspondence to Dr. David I. Rodenhiser, Room 4068, London Regional Cancer Centre, 790 Commissioner's Road East, London, Ontario, Canada, N6A 4L6. e-mail: drodenhi@uwo.ca

Received 9 May 2001; accepted 27 July 2001.
A.E. Anderson, T.R. Haines, D.P. Robinson, D.T. Butcher, B. Sadikovic, and D.I. Rodenhiser University of Western Ontario London Ontario, Canada

For reprints of this or any other article, contact Reprints@BioTechniques.com 